\title{
The glutathione reductase (GSR) polymorphisms (rs1002149 and rs8191009) and diabetic retinopathy in Slovenian subjects with type 2 diabetes mellitus
}

\author{
Ines Cilenšek ${ }^{1 \#}$, Sara Mankoč Ramuš ${ }^{1 \#}$, Mojca Globočnik Petrovič ${ }^{2}$ and Daniel Petrovič ${ }^{1 \# *}$ \\ ${ }^{1}$ Institute of Histology and Embryology, Faculty of Medicine, University of Ljubljana, Slovenia \\ ${ }^{2}$ Eye Clinic, University Medical Centre Ljubljana, Slovenia \\ \#Authors contributed equally
}

\begin{abstract}
The present work was carried out to evaluate a possible association between two polymorphisms (rs1002149 and rs8191009) in the GSR gene coding for antioxidant enzyme, and DR in 804 unrelated Slovene subjects (Caucasians) with T2DM. No differences were observed in genotype distribution between the two groups for either polymorphism in the GSR gene. No significant differences in serum 8-OHdG levels among subjects with DR stratified according to three possible genotypes were observed. In our study, we did not demonstrate an association between either rs1002149 or rs8191009 and DR in subjects with T2DM.
\end{abstract}

\section{Introduction}

Diabetic retinopathy (DR) is the most common microvascular complication of diabetes mellitus and affects between $3-4 \%$ of subjects in Europe [1]. It is the leading cause of acquired blindness in working age adults [2].

Interaction between hyperglycaemia, changes in the redox homeostasis, and oxidative stress are implied as the key events in the pathogenesis of DR [3]. The oxidative stress usually results from excessive reactive oxygen species (ROS) production, mitochondrial dysfunction, impaired antioxidant system, or a combination of these factors [4]. The retina has high content of polyunsaturated fatty acids and has the highest oxygen uptake and glucose oxidation relative to any other tissue; consequently it is more susceptible to oxidative stress $[3,4]$.

The enzyme glutathione reductase (gene nomenclature symbol $G S R$ ) is responsible for defence against oxidative stress caused by enhanced level of ROS. Mammalian GSR activity is present in both the cytosol and mitochondria [5]. The mitochondrial and cytosolic forms of mammalian GSR are biochemically indistinguishable, which suggests the two isoenzymes are encoded by a single nuclear gene [6]. The gene is located on chromosome 8p21.1 and consisting of 13 exons spanning $50 \mathrm{~kb}$ [7].

GSR and glutathione peroxidase (GPx) work in concert to counteract oxidative cellular damage [8]. GPx metabolizes hydrogen peroxide to water by using reduced glutathione as a hydrogen donor [9]. In cells, total glutathione can be free or bound to proteins [10]. Free glutathione is present mainly in its reduced form, following its reaction with ROS it is than oxidised and subsequently returned to its reduced state by GSR, using the cofactor NADPH generated by glucose 6-phosphate dehydrogenase [9,11]. The redox status depends on the relative amounts of the reduced and oxidized forms of glutathione (GSH/GSSG) and appears to be a critical determinant in cell. The regenerative reaction catalysed by GSR is therefore essential in antioxidant defence [8]. Interestingly GSR activity was reduced in the retina of diabetic rats [12]. Moreover in individuals with age-related macular degeneration (ARMD), disease suggested that may result in part from sequential series of steps initiated by ROS, significantly low blood GSR activities compared with controls was found [11].

Since long-term exposure to oxidative stress is strongly implicated in the pathogenesis of diabetic complications, polymorphic genes of detoxifying enzymes are implied in the development of DR. The aim of the present study was to examine a possible association of selected gene polymorphisms (rs1002149 and rs8191009) of the GSR gene and the development of DR in patients with type 2 diabetes mellitus (T2DM).

\section{Patients and methods}

In this cross-sectional case-control study 804 unrelated Caucasians with T2DM with a defined ophthalmologic status were enrolled (they have not been controlled for the glycaemic history). Patients were classified as having T2DM according to the current American Diabetes Association criteria [13].

Fundus examination was performed by a senior ophthalmologist (M.G.P.) after pupil dilatation (tropicamide and phenylephrine $2.5 \%$ ) using slit lamp biomicroscopy with non-contact lens, and was

Correspondence to: Daniel Petrovič, MD, PhD, Institute of Histology and Embryology, Medical Faculty of Ljubljana, Korytkova 2, SI-1105 Ljubljana, Slovenia, Tel: +386 1543 7367, Fax: +386 1543 7361, E-mail: daniel.petrovic@mf.uni-li.si

Key words: type 2 diabetes mellitus, diabetic retinopathy, oxidative stress, GSR gene polymorphisms

Received: November 20, 2016; Accepted: December 13, 2016; Published: December 13, 2016 

mellitus

electronically documented with a $50^{\circ}$-angle fundus camera (TopconTRC40-IX; Tokyo, Japan). Staging of DR was determined according to the ETDRS retinopathy severity scale [14].

The study group consisted of 804 subjects: 276 subjects with DR (cases) and the control group of 528 subjects with T2DM of more than 10 years' duration who had no clinical signs of DR.

To avoid the confounding effect of impaired kidney function, the patients with overt nephropathy were not enrolled. The study was approved by the national medical ethics committee. After an informed consent for the participation in the study was obtained, a detailed interview was made.

Blood samples for biochemical analyses: glycated haemoglobin (HbA1c), total cholesterol, triglyceride, high-density lipoprotein (HDL), low-density lipoprotein (LDL) cholesterol levels were collected after a 12-hour fasting period. All blood biochemical analyses were determined by standard techniques in an accredited biochemical laboratory. HbAlc was measured by high-performance liquid chromatography and had a non-diabetic range of 3.8-5.3\%. To assess the oxidative stress, serum levels of 8-hydroxy-2-deoxyguanosine (8OHdG) were measured with "High sensitive 8-OHdG check" enzymelinked immunosorbent assay (ELISA) kit (IBL International GMBH, Hamburg, Germany).

Genomic DNA was extracted from $200 \mu$ of whole blood using a FlexiGene DNA isolation kit according to the recommended protocol (Qiagene, Hilden; Germany). The rs1002149 and rs8191009 polymorphism of the GSR gene were genotyped by KBioscience Ltd using their novel fluorescence-based competitive allele-specific PCR (KASPar) assay. Details of the method used can be found at http:// www.kbioscience.co.uk/.

Chi-square test was used to compare discrete variables. Continuous clinical data were compared by unpaired Students $t$ test. In addition, all variables that showed significant differences by univariate methods (chi-square test, unpaired Students $t$ test) were analysed together in a logistic regression analysis. A $\mathrm{p}<0.05$ was considered statistically significant. One-way ANOVA was applied to evaluate the association of heterozygosity and homozygosity of studied SNPs with the serum levels of 8-OHdG. The deviation from Hardy-Weinberg equilibrium (HWE) was assessed by the exact test (http://ihg.gsf.de/) [15]. Statistical analysis was performed using the SPSS program for Windows version 20 (SPSS Inc. Illinois).

\section{Results}

Clinical and biochemical values of subjects with DR and control group are shown in Table 1. There were no differences in age, sex, prevalence of smoking and history of hypertension, systolic and diastolic blood pressure between the groups. Blood lipid levels, including HDL cholesterol and triglycerides, were not significantly different between the groups. On the other hand total cholesterol and LDL cholesterol levels were significantly higher. Subjects with DR had higher 8-OHdG levels compared to controls, but the difference was not statistically significant $(\mathrm{p}=0.4)$. Duration of diabetes was significantly longer in subjects with DR $(\mathrm{p}<0.001)$. Similarly, the prevalence of insulin therapy was significantly higher in subjects with $\mathrm{DR}(\mathrm{p}<0.001)$. Additionally, significant difference was observed in $\mathrm{BMI}$ and $\mathrm{HbA}_{1 \mathrm{c}}$ $(\mathrm{p}=0.01$ and $\mathrm{p}=0.001$, respectively; Table 1$)$.

The genotype and allele distribution of the tested polymorphisms in patients with DR and in patients without DR are shown in Table
Table 1. Clinical and laboratory characteristics of patients with DR and controls.

\begin{tabular}{|l|c|c|c|}
\hline Characteristics & Cases (276) & Controls (528) & P value \\
\hline Number & 276 & 528 & \\
\hline Age (years) & $64.8 \pm 8.0$ & $63.8 \pm 9.0$ & 0.1 \\
\hline Male sex (\%) & $152(55.1)$ & $280(53.1)$ & 0.3 \\
\hline Duration of diabetes (years) & $18.4 \pm 7.9$ & $12.5 \pm 6.6$ & $<\mathbf{0 . 0 0 1}$ \\
\hline Patients on insulin therapy (\%) & $217(78.6)$ & $254(48.1)$ & $<\mathbf{0 . 0 0 1}$ \\
\hline Systolic blood pressure (mm Hg) & $152.2 \pm 19.6$ & $149.8 \pm 19.6$ & 0.1 \\
\hline Diastolic blood pressure (mm Hg) & $83.4 \pm 11.2$ & $84.8 \pm 11.5$ & 0.1 \\
\hline BMI (kg/m $)$ & $29.8 \pm 4.8$ & $30.8 \pm 4.7$ & $\mathbf{0 . 0 1}$ \\
\hline History of hypertension (\%) & $238(86.1)$ & $441(83.5)$ & 0.2 \\
\hline Smokers (\%) & $16(5.9)$ & $40(7.6)$ & 0.5 \\
\hline Total cholesterol (mmol/l) & $4.8 \pm 1.2$ & $4.6 \pm 1.0$ & $\mathbf{0 . 0 4}$ \\
\hline LDL cholesterol (mmol/l) & $2.8 \pm 0.9$ & $2.6 \pm 0.8$ & $\mathbf{0 . 0 0 4}$ \\
\hline HDL cholesterol (mmol/l) & $1.2 \pm 0.3$ & $1.2 \pm 0.4$ & 0.6 \\
\hline Triglycerides (mmol/l) & $2.0 \pm 1.7$ & $2.1 \pm 1.5$ & 0.4 \\
\hline 8-OHdG & $1.7 \pm 0.9$ & $1.5 \pm 0.5$ & 0.4 \\
\hline HbA $(\%) *$ & $8.0 \pm 1.3$ & $7.7 \pm 1.1$ & $\mathbf{0 . 0 0 1}$ \\
\hline
\end{tabular}

The values represent mean \pm standard deviation. Bold indicates statistically significant results.

$*$ The average value for haemoglobin $\mathrm{A}_{1 \mathrm{C}}\left(\mathrm{HbA}_{1 \mathrm{c}}\right)$.

Table 2. Genotype and allele distribution of rs 1002149 and rs8191009 polymorphisms in T2DM patients with and without DR.

\begin{tabular}{|l|c|c|c|}
\hline & Cases (276) & Controls (528) & p value \\
\hline rs1002149 & & & \\
\hline TT & $8(2.9)$ & $9(1.7)$ & \\
\hline TG & $72(26.2)$ & $152(28.7)$ & 0.4 \\
\hline GG & $196(70.9)$ & $367(69.6)$ & \\
\hline T allele (\%) & $88(15.9)$ & $170(16.1)$ & 0.9 \\
\hline G allele (\%) & $464(84.1)$ & $886(83.9)$ & \\
\hline PHWE† $\dagger$ & 0.7 & 0.1 & \\
\hline rs8191009 & $14(5.1)$ & $15(2.8)$ & \\
\hline AA & $88(31.9)$ & $175(33.1)$ & \\
\hline GA & $174(63.0)$ & $338(64.0)$ & \\
\hline GG & $116(21.0)$ & $205(19.4)$ & \\
\hline A allele (\%) & $436(79.0)$ & $851(80.6)$ & \\
\hline G allele (\%) & 0.5 & 0.2 & \\
\hline PHWE $\dagger$ & & & \\
\hline
\end{tabular}

PHWE $\uparrow$ values were computed using Pearson's goodness-of-fit chi-square (1 df).

2. The frequency of genotypes did not deviate significantly from the Hardy-Weinberg equilibrium (Table 2).

No significant differences in allele frequencies between subjects with DR and controls were noted. For the rs1002149 polymorphism the allelic frequencies among controls were $16.1 \%$ and $83.9 \%$ for the $\mathrm{T}$ and $\mathrm{G}$ alleles, respectively. Moreover, among subjects with $\mathrm{DR}$, the allelic frequencies were $15.9 \%$ for the $\mathrm{T}$ and $84.1 \%$ for the $\mathrm{G}$ allele, respectively.

Similarly we found no statistically significant differences in allele frequencies between subjects with DR and controls for the rs8191009 polymorphism. The allelic frequencies among controls were $19.4 \%$ and $80.6 \%$ for the A and G alleles, respectively. Moreover, among subjects with DR, the allelic frequencies were $21.0 \%$ for the A and $79.0 \%$ for the G allele.

No differences were observed in genotype distribution between the two groups for either polymorphism in the GSR gene.

The results of logistic regression analyses are listed in Table 3. None of the homozygous carriers of both SNPs (TT for rs1002149 and AA 
Cilenšek I (2016) The glutathione reductase (GSR) polymorphisms (rs1002149 and rs8191009) and diabetic retinopathy in Slovenian subjects with type 2 diabetes mellitus

Table 3. Logistic regression analysis adjusted for different confounders (duration of diabetes, patients on insulin therapy, BMI, total cholesterol, LDL cholesterol, HbA ${ }_{1 \mathrm{c}}$ ) according to codominant genetic model.

\begin{tabular}{|c|c|c|c|c|c|}
\hline Inheritance model & Genotype & Cases (276) & Controls (528) & Unadjusted OR, $95 \%$ CI/p value & Adjusted OR, $95 \% \mathrm{CI} / \mathrm{p} \dagger$ value \\
\hline rs1002149 & TT & $8(2.9)$ & $9(1.7)$ & $1.65(0.63-4.34) / 0.3$ & $4.36(0.69-27.59) / 0.1$ \\
\hline \multirow[t]{2}{*}{ Co-dominant } & TG & $72(26.2)$ & $152(28.7)$ & $0.89(0.64-1.24) / 0.5$ & $1.07(0.64-1.81) / 0.8$ \\
\hline & GG & $196(70.9)$ & $367(69.6)$ & reference & reference \\
\hline rs8191009 & AA & $14(5.1)$ & $15(2.8)$ & $1.81(0.86-3.84) / 0.1$ & $0.59(0.15-2.30) / 0.4$ \\
\hline \multirow[t]{2}{*}{ Co-dominant } & GA & $88(31.9)$ & $175(33.1)$ & $0.98(0.71-1.33) / 0.9$ & $0.65(0.39-1.08) / 0.1$ \\
\hline & GG & $174(63.0)$ & $338(64.0)$ & reference & reference \\
\hline
\end{tabular}

$P \dagger$ values were adjusted for duration of diabetes, patients on insulin therapy, BMI, total cholesterol, LDL cholesterol, HbAlc

OR: odds ratio, CI: confidence interval

Table 4. The serum 8-OHdG levels in a subpopulation of 30 diabetics with DR according to different genotypes of rs1002149 and rs8191009 polymorphisms.

\begin{tabular}{|c|c|c|c|}
\hline polymorphism & $\begin{array}{c}\text { Genotype } \\
\text { (number) }\end{array}$ & 8-OHdG (ng/ml) & \multirow{2}{*}{ P value } \\
\hline \multirow{2}{*}{ rs1002149 } & TT (0) & - & \multirow{2}{*}{0.5} \\
\cline { 2 - 3 } & TG (6) & $1.92 \pm 1.07(0.79-3.04)$ & \multirow{2}{*}{} \\
\cline { 2 - 3 } & GG (24) & $0.97 \pm 0.19(1.18-2.00)$ & \multirow{2}{*}{0.8} \\
\hline & AA (2) & $1.26 \pm 0.38(0.91-4.72)$ & \\
\hline \multirow{2}{*}{ rs8191009 } & GA (9) & $1.81 \pm 0.87(1.14-2.48)$ & \\
\hline & GG (19) & $1.66 \pm 0.98(1.10-2.15)$ & \\
\hline
\end{tabular}

Values are mean $\pm \mathrm{SD}(95 \%$ confidence interval).

for rs8191009, respectively) showed statistically significant association with DR before and after adjustment for confounding variables ( $\mathrm{p}=0.3$ and $\mathrm{p}=0.1$ for $\mathrm{rs} 1002149 ; \mathrm{p}=0.1$ and $\mathrm{p}=0.4$ for $\mathrm{rs} 8191009$ ). Moreover, the results show that heterozygosity of both SNPs (TG for rs1002149 and GA for rs8191009, respectively) could provide a protective effect against $\mathrm{DR}$, but again, the association was not significant ( $\mathrm{p}=0.5$ and $\mathrm{p}=0.8$ for rs1002149; $\mathrm{p}=0.9$ and $\mathrm{p}=0.1$ for $\mathrm{rs} 8191009$ ).

Next, we assessed for differences in serum 8-OHdG levels according to GSR genotypes for both SNPs. As shown in Table 4, there were no significant differences in serum 8-OHdG levels in the group of subjects with DR.

\section{Discussion}

The present work was carried out to evaluate a possible association between two polymorphisms (rs1002149 and rs8191009) in the GSR gene coding for antioxidant enzyme, and DR in 804 unrelated Slovene subjects (Caucasians) with T2DM. In our study, we did not demonstrate an association between either rs 1002149 or rs8191009 and DR in subjects with T2DM.

Polymorphisms in the GSR gene have been associated with postmenopausal bone mineral density values [16] and chronic obstructive pulmonary disease [17]. To our knowledge, no studies have considered the relationship between GSR gene variants and DR although GSR plays an important role in the defence against oxidative stress, through the reduction of GSSG to GSH. Abnormal GSH status is involved in $\beta$-cell dysfunction and in the pathogenesis of long-term complications of diabetes. The dysregulation is widely implicated in disease states [18].

The investigation of the distribution of minor-allele frequencies (MAF) of the rs1002149 revealed subtle difference in comparison with the allele frequency distribution in 468 postmenopausal Slovenian women in the study of Jurkovic-Mlakar et al. [16]. The $\mathrm{T}$ allele had an intermediate frequency ( $15.9 \%$ in cases and $16.1 \%$ in controls) and exhibited a slightly lower frequency with respect to the frequency observed in Slovenian postmenopausal women with MAF of $18.3 \%$.
Under the assumption of the co-dominant genetic model of inheritance we have found no evidence that rs1002149 and rs8191009 in GSR are associated with the risk for DR. Additionally, none of the tested SNPs reached statistical significance in the multivariate models adjusted for univariate significant clinical covariates.

In the present study, $\mathrm{HbAlc}$ was significantly elevated in subjects with DR. It is found that a poor metabolic control which was demonstrated by high HbAlc levels was directly proportional to the prevalence of DR, which has been documented by Klein et al. [19]. In 2005 , Brownlee [20] proposed a unifying mechanism that interconnects the hyperglycaemia-induced processes, and, in the initial observation, hyperglycaemia was proven to increase oxidative stress and ROS production related to diabetic damage. Obviously, the oxidative stress has been implicated as a causative factor in the development of DR. In the light of this fact we assessed the oxidative stress status of type 2 DM subjects with measuring the serum 8-OHdG levels. Since there was a significant elevation of the total and LDL cholesterol, HbAlc and longer duration of diabetes in subjects with DR, we would expect that the p-value for a marker of oxidative stress to DNA would be significant, but this was not the case in our samples. Of note, there were no significant differences between those subjects with and without DR $(\mathrm{p}=0.4)$. It should be mentioned, however, that diabetic patients with hyperlipidaemia were undergoing statin treatment. Statins were prescribed in $79.3 \%$ DM2 subjects with DR and in $80.9 \%$ subjects without DR (data not shown). Statin use has been shown to be effective as it reduces LDL and triglycerides and increases HDL [21,22]. In addition, there is evidence that statins have antioxidant activity [23]. Statins have documented vasculoprotective effects. The protective action of statins on the retinal microvasculature is mediated through antioxidant and anti-inflammatory properties independent of their cholesterol-lowering activity [24,25]. Although suggestive, the current evidence is still not adequate to definitively support the primary use statins to reduce the risk of development or progression of DR [26]. In spite of the lack of definite associations between traditional lipid markers and DR, lipid-lowering therapy may be an effective adjunctive agent for DR [27].

Further, serum 8-OHdG levels among subjects with DR stratified according to three possible genotypes for each polymorphism were compared. Serum 8-OHdG levels were measured in 70 subjects without DR and 30 with DR. Again, no association was found between GSR genotypes and 8-OHdG level ( $\mathrm{p}=0.5$ for $\mathrm{rs} 1002149$ and $\mathrm{p}=0.8$ for rs8191009) in subjects with DR. It is important to realize that lack of significance may be attributed to the scarcity of data $(\mathrm{N}=100)$, since studies with inadequate sample size have insufficient power to detect real associations. Apart from strand breaks in DNA, ROS can cause oxidation of guanine residues to $8-\mathrm{OHdG}$ which has been widely used as a biomarker of oxidative DNA damage, and measurement of its level is applied to evaluate the load of oxidative stress $[28,29]$. The content 

mellitus

of the 8-OHdG in the urine, serum and mononuclear cells of patients with type 2 diabetes with either retinopathy or nephropathy were much higher than those in patients without complication [30-32].

Proteins can also be modified and become cytotoxic by ROS and reactive nitrogen species (RNS), thus contributing to the development of DR. Advanced oxidation protein products (AOPPs) were first detected in the plasma of chronic uremic patients, and are considered to be a novel marker of oxidative stress because it is stable and easy to detect [33]. Besides, the few studies that have suggested that AOPP plays a role in DR or proliferative diabetic retinopathy $[30,34,35]$ Taylor et al. [36] have identified inconsistencies in the published protocols by which AOPP is measured.

The more recent study from Zhang et al. [37] has also shown that in the case of an association between GSR polymorphisms and low anti-oxidant glutathione reducing activity increased AOPP values would be the direct consequence of any inflammatory response or oxidation by the malaria parasite growing in red blood cells. Thus, further investigations examining the associations of variations of the GSR gene with development of DR or with the biomarker AOPP would be appritiated.

In addition to inducing DNA damage, the effects of cellular oxidants have also been related to activation of transcription factors. The most significant effects of oxidants on signalling pathways have been observed in the nuclear factor erythroid 2-related factor 2 (NRF2) and nuclear factor (NF-kB) pathways [38]. Among antioxidant proteins, NRF2 controls the expression of direct ROS scavenging enzymes such as GPx and SOD; GSH generating enzymes such as the catalytic and modifier subunit of $\gamma$-glutamate cysteine ligase, GSR; and thiol molecules such as thioredoxin [39]. If stress is not present NRF2 is trapped in the cytosol bound to Kelch like-ECH-associated protein 1 (Keap1). But during oxidative stress it dissociates from Keap 1 and moves into the nucleus where it binds with the antioxidant response element (ARE). GSH is one of the products of this activation.

Data from human diabetic retinas show increased retinal NRF2 despite low levels of GSH, suggesting that the signalling cascade is impaired in DR. Lastly; this indicates that there may be an underlying molecular interconnection between NRF2, GSR, GSH, but further studies are required to understand the role of antioxidant defence system in the pathogenesis of DR.

In conclusion, our previously studies have reported associations of the polymorphisms in the oxidative stress pathway genes [40-43] and the risk for DR, however, our current association tests which were restricted to only two variations (namely, rs1002149 and rs8191009) in the GSR gene were not significant. Nevertheless, to date no comprehensive survey on GSR polymorphisms and the risk for DR is available; indicating that future studies of common variants across not only of the GSR, but also of the NRF2 gene may prove to be more fruitful to unravel the complexity of oxidative stress in DR.

\section{References}

1. Nentwich MM1, Ulbig MW1 (2015) Diabetic retinopathy - ocular complications of diabetes mellitus. World J Diabetes 6: 489-499. [Crossref]

2. Madsen-Bouterse SA, Kowluru RA (2008) Oxidative stress and diabetic retinopathy: pathophysiological mechanisms and treatment perspectives. Rev Endocr Metab Disord 9: 315-327. [Crossref]

3. Kowluru RA, Chan PS (2007) Oxidative stress and diabetic retinopathy. Exp Diabetes Res: 43603. [Crossref]

4. Nita M, Grzybowski A (2016) The Role of the Reactive Oxygen Species and Oxidative
Stress in the Pathomechanism of the Age-Related Ocular Diseases and Other Pathologies of the Anterior and Posterior Eye Segments in Adults. Oxid Med Cell Longev: 3164734. [Crossref]

5. Deponte M (2013) Glutathione catalysis and the reaction mechanisms of glutathionedependent enzymes. Biochim Biophys Acta 1830: 3217-3266. [Crossref]

6. Kelner MJ, Montoya MA (2000) Structural organization of the human glutathione reductase gene: determination of correct cDNA sequence and identification of a mitochondrial leader sequence. Biochem Biophys Res Commun 269: 366-368. [Crossref]

7. Kamerbeek NM, van Zwieten R, de Boer M, Morren G, Vuil H, et al. (2007) Molecular basis of glutathione reductase deficiency in human blood cells. Blood 109: 3560-3566. [Crossref]

8. Hassan MQ, Hadi RA, Al-Rawi ZS, Padron VA, Stohs SJ (2001) The glutathione defense system in the pathogenesis of rheumatoid arthritis. $J$ Appl Toxicol 21: 69-73. [Crossref]

9. Maritim AC, Sanders RA, Watkins JB 3rd (2003) Diabetes, oxidative stress, and antioxidants: a review. J Biochem Mol Toxicol 17: 24-38. [Crossref]

10. Pastore A, Federici G, Bertini E, Piemonte F (2003) Analysis of glutathione: implication in redox and detoxification. Clin Chim Acta 333: 19-39. [Crossref]

11. Cohen SM, Olin KL, Feuer WJ, Hjelmeland L, Keen CL, et al. (1994) Low glutathione reductase and peroxidase activity in age-related macular degeneration. $\mathrm{Br} \mathrm{J}$ Ophthalmol 78: 791-794. [Crossref]

12. Obrosova IG, Drel VR, Kumagai AK, Szábo C, Pacher P, et al. (2006) Early diabetesinduced biochemical changes in the retina: comparison of rat and mouse models. Diabetologia 49: 2525-2533. [Crossref]

13. Genuth S, Alberti KG, Bennett P, Buse J, Defronzo R, et al. (2003) Follow-up report on the diagnosis of diabetes mellitus. Diabetes Care 26: 3160-3167. [Crossref]

14. (1991) Grading diabetic retinopathy from stereoscopic color fundus photographs - an extension of the modified Airlie House classification. ETDRS report number 10. Early Treatment Diabetic Retinopathy Study Research Group. Ophthalmology 98: 786-806. [Crossref]

15. Elston RC, Forthofer R (1977) Testing for Hardy-Weinberg equilibriumin smal samples. Biometrics 33: 536-542.

16. Mlakar SJ, Osredkar J, Prezelj J, Marc J (2012) Antioxidant enzymes GSR, SOD1, SOD2, and CAT gene variants and bone mineral density values in postmenopausa women: a genetic association analysis. Menopause 19: 368-376. [Crossref]

17. Bentley AR, Emrani P, Cassano PA (2008) Genetic variation and gene expression in antioxidant related enzymes and risk of COPD: a systematic review. Thorax 63: 956 961. [Crossref]

18. http://dvd.sagepub.com/content/7/6/258.abstract

19. Klein R, Klein BE, Moss SE, Davis MD, DeMets DL (1988) Glycosylated hemoglobin predicts the incidence and progression of diabetic retinopathy. JAMA 260: 2864-2871. [Crossref]

20. Brownlee M (2005) The pathobiology of diabetic complications: a unifying mechanism. Diabetes 54: 1615-1625. [Crossref]

21. Redberg RF, Katz MH (2012) Reassessing benefits and risks of statins. $N$ Engl $J$ Med 367: 776. [Crossref]

22. Colhoun HM, Betteridge DJ, Durrington PN, Hitman GA, Neil HA, et al. (2004) CARDS investigators. Primary prevention of cardiovascular disease with atorvastatin in type 2 diabetes in the Collaborative atorvastatin Diabetes Study (CARDS): multicentre randomised placebo-controlled trial. Lancet 364: 685-696. [Crossref]

23. Franzoni F, Quińones-Galvan A, Regoli F, Ferrannini E, Galetta F (2003) A comparative study of the in vitro antioxidant activity of statins. Int J Cardiol 90: 317-321. [Crossref]

24. Bellosta S, Ferri N, Bernini F, Paoletti R, Corsini A (2000) Non-lipid-related effects of statins. Ann Med 32: 164-176. [Crossref]

25. Danesh FR, Kanwar YS (2004) Modulatory effects of HMG-CoA reductase inhibitors in diabetic microangiopathy. FASEB $J$ 18: 805-815. [Crossref]

26. Fioretto P, Dodson PM, Ziegler D, Rosenson RS (2010) Residual microvascular risk in diabetes: unmet needs and future directions. Nat Rev Endocrinol 6: 19-25. [Crossref]

27. Chang YC, Wu WC (2013) Dyslipidemia and diabetic retinopathy. Rev Diabet Stud 10 121-132. [Crossref]

28. Gao CM, Takezaki T, Wu JZ, Liu YT, Ding JH, et al. () Polymorphisms in thymidylate 

mellitus

synthase and methylenetetrahydrofolate reductase genes and the susceptibility to esophageal and stomach cancer with smoking. Asian Pac J Cancer Prev 5: 133-138. [Crossref]

29. Huang CY, Wilson MW, Lay LT, Chow CK, Robertson LW, et al. (1994) Increased 8-hydroxydeoxyguanosine in hepatic DNA of rats treated with the peroxisome proliferators ciprofibrate and perfluorodecanoic acid. Cancer Lett 87: 223-228. [Crossref]

30. Pan HZ, Zhang H, Chang D, Li H, Sui H (2008) The change of oxidative stress products in diabetes mellitus and diabetic retinopathy. Br J Ophthalmol 92: 548-551. [Crossref]

31. Wakabayashi Y, Usui Y, Shibauchi Y, Uchino H, Goto H (2010) Increased levels of 8-hydroxydeoxyguanosine in the vitreous of patients with diabetic retinopathy. Diabetes Res Clin Pract 89: e59-61. [Crossref]

32. Kakimoto M, Inoguchi T, Sonta T, Yu HY, Imamura M, et al. (2002) Accumulation of 8-hydroxy-2'-deoxyguanosine and mitochondrial DNA deletion in kidney of diabetic rats. Diabetes 51: 1588-1595. [Crossref]

33. Witko-Sarsat V, Friedlander M, Capeillčre-Blandin C, Nguyen-Khoa T, Nguyen AT, et al. (1996) Advanced oxidation protein products as a novel marker of oxidative stress in uremia. Kidney Int 49: 1304-1313. [Crossref]

34. Tabak O, Gelisgen R, Erman H, Erdenen F, Muderrisoglu C, et al. (2011) Oxidative lipid, protein, and DNA damage as oxidative stress markers in vascular complications of diabetes mellitus. Clin Invest Med 34: E163-171. [Crossref]

35. Brzovic-Šaric V, Landeka I, Šaric B, Barberic M, Andrijaševic L, et al. (2015) Levels of selected oxidative stress markers in the vitreous and serum of diabetic retinopathy patients. Mol Vis 21: 649-664. [Crossref]

36. Taylor EL, Armstrong KR, Perrett D, Hattersley AT, Winyard PG (2015) Optimisation of an Advanced Oxidation Protein Products Assay: Its Application to Studies of Oxidative Stress in Diabetes Mellitus. Oxid Med Cell Longev: 496271.

37. Zhang G, Skorokhod OA, Khoo SK, Aguilar R, Wiertsema S, et al. (2014) Plasma advanced oxidative protein products are associated with anti-oxidative stress pathway genes and malaria in a longitudinal cohort. Malar J 13: 134. [Crossref]

38. Kensler TW, Wakabayashi N, Biswal S (2007) Cell survival responses to environmental stresses via the Keap1-Nrf2-ARE pathway. Annu Rev Pharmacol Toxicol 47: 89-116. [Crossref]

39. Choi BH, Kang KS, Kwak MK (2014) Effect of redox modulating NRF2 activators on chronic kidney disease. Molecules 19: 12727-12759. [Crossref]

40. Petrovic MG, Cilensek I, Petrovic D (2008) Manganese superoxide dismutase gen polymorphism (V16A) is associated with diabetic retinopathy in Slovene (Caucasians) type 2 diabetes patients. Dis Markers 24: 59-64. [Crossref]

41. Cilenšek I, Mankoc S, Petrovic MG, Petrovic D (2012) GSTT1 null genotype is a risk factor for diabetic retinopathy in Caucasians with type 2 diabetes, whereas GSTM1 null genotype might confer protection against retinopathy. Dis Markers 32: 93-99. [Crossref]

42. Cilenšek I, Mankoc S, Globocnik Petrovic M, Petrovic D (2012) The 4a/4a genotype of the VNTR polymorphism for endothelial nitric oxide synthase (eNOS) gene predicts risk for proliferative diabetic retinopathy in Slovenian patients (Caucasians) with type 2 diabetes mellitus. Mol Biol Rep 39: 7061-7067. [Crossref]

43. Ramus SM, Cilensek I, Petrovic MG, Soucek M, Kruzliak P, et al. (2016) Single nucleotide polymorphisms in the Trx2/TXNIP and TrxR2 genes of the mitochondria thioredoxin antioxidant system and the risk of diabetic retinopathy in patients with Type 2 diabetes mellitus. J Diabetes Complications 30: 192-198. [Crossref]

Copyright: (C2016 Cilenšek I. This is an open-access article distributed under the terms of the Creative Commons Attribution License, which permits unrestricted use, distribution, and reproduction in any medium, provided the original author and source are credited. 